\title{
EFFECT OF GLYCIDYL METHACRYLATE ON WATER ABSORPTION PROPERTIES OF SAGO HAMPAS BIOCOMPOSITE
}

\author{
M. S. Jamaludin ${ }^{1}$, A. Zulkharnain ${ }^{2}$, A. A. Khan $^{3}$ and N. Wagiman ${ }^{4}$ \\ ${ }^{1,3,4}$ Department of Mechanical and Manufacturing, Universiti Malaysia Sarawak, 93000, Kota Samarahan, Sarawak, \\ Malaysia \\ ${ }^{2}$ Department of Molecular Biology, Universiti Malaysia Sarawak, 93000, Kota Samarahan, Sarawak, Malaysia
}

Date received: 13/08/2015, Date accepted: 25/08/2015

Corresponding author's email: jmsyahmi@unimas.my

\begin{abstract}
This study examines the water absorption of sago hampas biocomposite utilizing glycidyl methacrylate as its matrix. Composites were fabricated with 25, 30, $40 \mathrm{wt} \%$ sago hampas content and another sample of pure sago hampas using hydraulics hot press machine. The water absorption properties of composites with different sago hampas composition were investigated according to Standard Test Method for Tensile Properties of Polymer Matrix Composite Materials of ASTM D570. Water absorption of pure sago hampas composite have the highest average water absorption percentage with 59.1 $\mathrm{wt} \%$ as compared to the lowest average water absorption percentage recorded for $30 \mathrm{wt} \%$ sago hampas content biocomposite with $16.8 \%$. However sago hampas loading was increased resulting in the increased in average water absorption on biocomposite for $40 \mathrm{wt} \%$ sago hampas content which is $33.1 \%$.
\end{abstract}

Keywords: Glycidyl mehacrylate, sago hampas, biocomposite, water absorption test

\subsection{INTRODUCTION}

Most composites produced nowadays uses non-degradable fibers made from non-renewable resource. This is to produce high durability product and to ensure product longevity. However the use of plastic materials in agriculture causes serious hazards to the environment [1]. The introduction of biodegradable materials, which can be disposed directly into soil can be one possible solution to this problem. Sago hampas $(\mathrm{SH})$ is an abundantly available agricultural waste which has contributed to environment pollution. From previous study, it has been proven that sago hampas contains cellulose, hemicellulose and lignin [2]. The production of natural biocomposite is formed by matrix (resin) and reinforcements (fiber) mainly formed by cellulose [3] and which is available in SH. Natural biocomposite can be define as composites made up of natural fibers and is readily degradable.

Natural fibers are produced by plants and animals. Plants fibers include seed hair (eg. cotton), stem, (eg. hemp), leaf fibers (eg. sisal) and husk fibers (eg. sago). Animal fibers include wool (eg. angora wool and alpaca wool) and secretions (eg. silk). Natural biocomposite research areas are divided into three which are short natural fiber research, long natural fiber research and biopolymer development research [4]. The interest on the usage of natural fibers as fillers is very high due to its low density, more biodegradable and non-abrasiveness during processing [5]. This research will focus on short natural fiber research which utilizes 'waste' cellulose fiber which is sago hampas

In this study, glycidyl methacrylate (GMA) were used as it is less harmful to human body compared to other reagent [6] and have balance chemical and mechanical properties. GMA is selected as the matrix due to the ease of handling it in room temperature [6]. GMA was utilized in many studies to facilitate chemical reaction between components (polypropelene and fiber) during melt mixing [6]. GMA will be utilized directly with sago hampas $(\mathrm{SH})$ to produce composite. This research mainly focuses on formulating composite material utilizing sago hampas and glycidyl methacrylate (GMA) and testing its water absorption test was conducted. Based on Sahari et al, (2012) water absorption test on biocomposite is done for quality control as water absorption affects the mechanical properties of 
composites. Besides that water absorption by biocomposites using natural fibers will affect its long term performance [7]. The water absorbed leads to physical degradation such as dimensional changes and thickness swelling [8].

\subsection{METHODOLOGY}

The biofillers used was sago hampas (SH) obtained from River Link Sago Resources Sdn. Bhd. Mukah, Sarawak. Glycidyl Methacrylate (GMA, CAS 106-91-2) was purchased from Aldrich.

SH was washed to remove dirt from milling machine, sago starch and starchy granules of sago bark leftovers and was immersed in distilled water at $90^{\circ} \mathrm{C}$ for $6 \mathrm{~h}$ to allow to destarched. The resulting slurry was washed thoroughly under running water to remove starch extractions. SH obtained was dried using an air oven at $60^{\circ} \mathrm{C}$ for $24 \mathrm{~h}$. Treated SH was mixed in GMA epoxy and glycerol to increase fluidity, at room temperature according to the desired volume fractions as shown in the Table 1.

Table 1 Biocomposite mixing conditions

\begin{tabular}{|c|c|c|c|}
\hline SH Content (wt $\%)$ & SH weight (g) & GMA weight (g) & Glycerol weight (g) \\
\hline Pure SH & 10 & 0 & 0 \\
\hline 25 & 5 & 10 & 5 \\
\hline 30 & 7 & 10 & 5 \\
\hline 40 & 10 & 10 & 5 \\
\hline
\end{tabular}

The design of biocomposite films were referred to standard ASTM D3039/D3039M international specimen geometry requirements shown in Table 2. The mixing solution was poured in moulds of 7 columns with $0.25 \mathrm{~cm}$ thick, $27 \mathrm{~cm}$ length and $2.5 \mathrm{~cm}$ width. Then the mould with composite mixture was placed under hydraulic hot press machine. The assembly was then pressed for $1 \mathrm{~h}$ with $160^{\circ} \mathrm{C}$ on both upper and lower plates [9]. Composite was left to cool down under room temperature before taken out from mould and cut into $5 \mathrm{~cm}$ films as shown in Figure 2. SH/GMA biocomposite was tested at 25, 30 and $40 \mathrm{wt} \%$ ratio. Then the SH/GMA biocomposite will be compared based on its effect on mechanical properties with pure $\mathrm{SH}$.

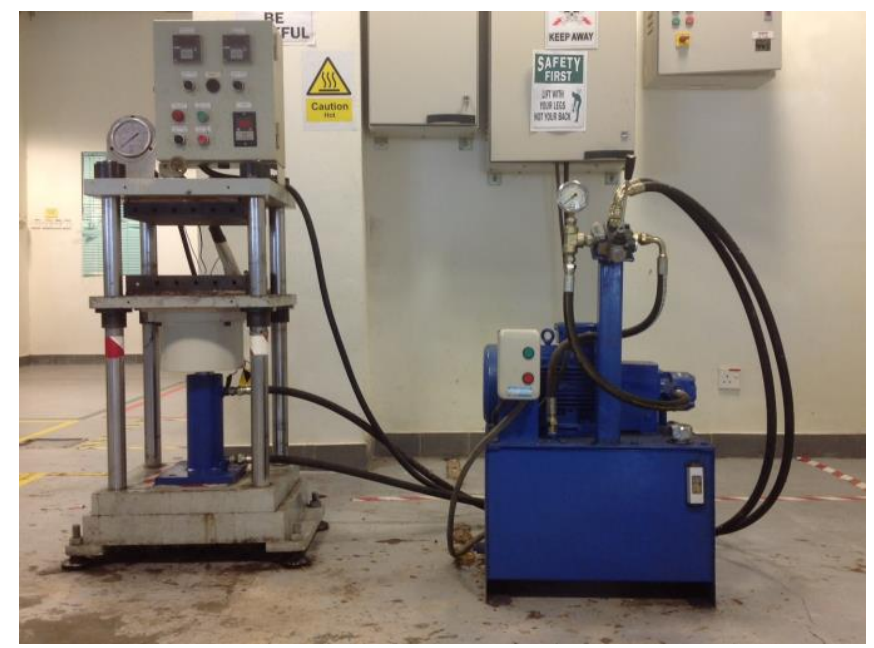

Figure 1 Hydraulic hot-press machine 
Table 2 Tensile sample geometry requirement

\begin{tabular}{lc}
\hline Parameter & Requirement \\
\hline Shape & Constant rectangular cross-section \\
Min. length & Gripping +2 times width + gage length \\
Sample width & as needed \\
Sample width tolerance & $\pm 1 \%$ of width \\
Sample thickness & as needed \\
Sample thickness tolerance & $\pm 4 \%$ of thickness \\
Sample flatness & Flat with light finger pressure \\
\hline
\end{tabular}

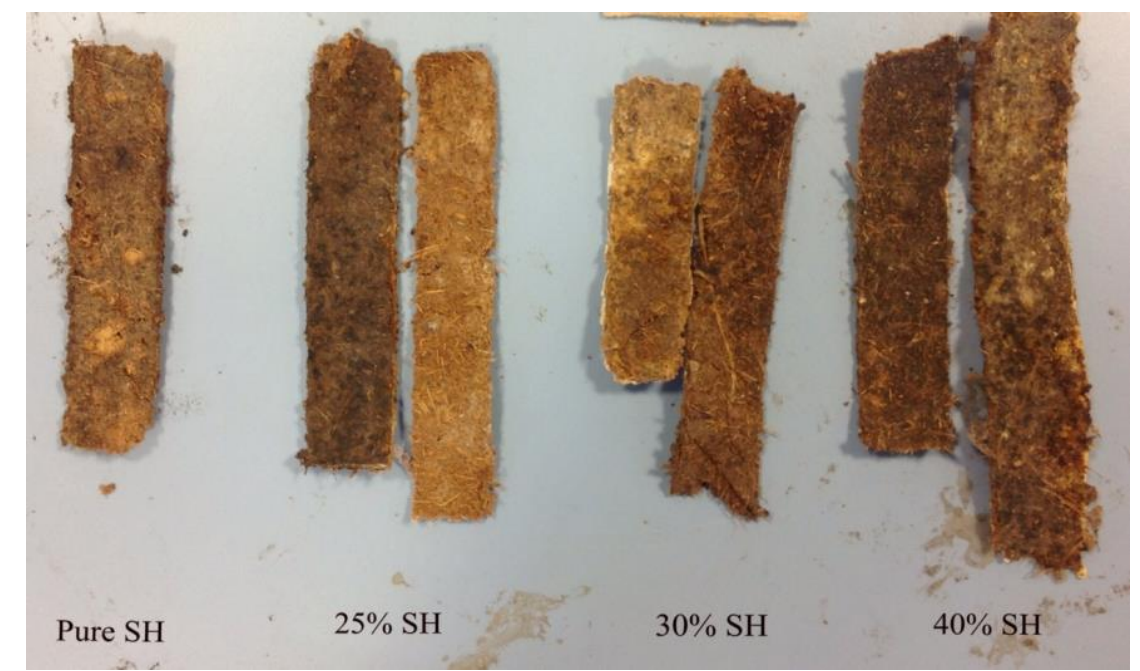

Figure 2 SH/GMA biocomposite films

Water absorption was determined according to ASTM D570 on rectangular samples with thickness of $0.25 \mathrm{~cm}$, length of $7 \mathrm{~cm}$, and width of $2.5 \mathrm{~cm}$. Three replicates of each samples of different $\mathrm{SH}$ composition was prepared. The samples were dried in an oven for $24 \mathrm{hrs}$ at $60^{\circ} \mathrm{C}$ and then placed in desiccator to cool. After cooled, samples were emerged in distilled water at room temperature up to 4 hours. The samples were simultaneously taken out from the water tank at 4 hours mark, dried with lint free cloth and subsequently weighted. The amount of water uptake by samples was calculated using the following equation referring to ASTM D570. The volume of water absorbed by sample is reported as percentage of water absorption as shown in Equation 1:

Percentage of water absorption $(\%)=[$ (wet weight - dry weight $) /$ dry weight $] \mathrm{x} 100$

\subsection{RESULTS AND ANALYSIS}

Water absorption test results obtained from this study is reported referring to Table 4. Based on the Table 4, the percentage of water absorption for pure $\mathrm{SH}$ composite was the highest average water absorption percentage recorded which is $59.1 \%$ and the lowest water absorption percentage was composite with 30 wt $\%$ SH content with $16.8 \%$. Based on Taib et al (2008), natural fiber is hydrophilic which explains the high water absorptivity of the pure SH composite. With the addition of matrix, reduces the water absorption of the composite [4], in this case the matrix is GMA. 
Table 4 Average water absorption percentage

\begin{tabular}{cc}
\hline SH Content $($ wt $\%)$ & Water Absorption $(\%)$ \\
\hline Pure SH & \pm 59.1 \\
25 & \pm 50.8 \\
30 & \pm 16.8 \\
40 & \pm 33.1 \\
\hline
\end{tabular}

The addition of GMA helps to reduce the average percentage of water absorption of composite by forming an interfacial bond between matrix and fiber [8]. This can be proved because pure $\mathrm{SH}$ composite has a higher average water absorption percentage which is $59.1 \%$ compared to water absorption percentage of composite with $25 \mathrm{wt} \% \mathrm{SH}$ content with $50.8 \%$. Without matrix, pure fibers will have gaps and this increases the percentage of water uptake [15] as water molecules diffuse into pores and micro-cracks within the composite. In the other hand, water absorption by $30 \mathrm{wt} \% \mathrm{SH}$ content biocomposite is $16.8 \%$ which is lower compared to the average water absorption percentage of the 25 wt\% biocomposite. Scientist reported that the increase in fibre loading in biocomposite results in reduction of water absorption because the fiber acts as water resistant in biocomposite [8]. When $\mathrm{SH}$ load was increased from $25 \mathrm{wt} \%$ to $30 \mathrm{wt} \%$, interfacial bond between SH and GMA becomes greater. It is believed that the interfacacial bond resist the water molecules from penetrating into the interface of the biocomposite, hence slowing down the initial rate of water absorption. Thus, result in the lower percentage of water absortion of biocomposite with $30 \mathrm{wt} \% \mathrm{SH}$ compared to $25 \mathrm{wt} \% \mathrm{of} \mathrm{SH}$.

However, 40 wt $\%$ SH content biocomposite has a higher average water absorption percentage with $33.1 \%$ as compared to the $30 \mathrm{wt} \% \mathrm{SH}$ content biocomposite with $16.8 \%$. As the amount of SH becomes too much in a biocomposite, the fiber acts more to its hydrophilic nature rather than hindrance towards water molecule [16]. The hydrophilic characteristic of natural fibre is the result of polysaccharide hydroxyl group found in cellulose which produces hydrogen bond between water and SH fiber [11]. Thus, increasing SH fiber loading to $40 \mathrm{wt} \%$ will only increase the hydrogen bond formed which allow water molecule to actively attack the biocomposite interface resulting in the increase water absorption properties of the biocomposite.

\subsection{CONCLUSIONS}

The results of study are discussed as follows. SH/GMA biocomposite can be further tested on morphological testing using SEM to view on the surface and adhesion of fiber to resin to explain on the relatively low average tensile strength. Furthermore, water absorption test was done to SH/GMA biocomposite to investigate the water uptake of the biocomposite formulated. The addition of matrix reduces water absorption properties of biocomposite. However the increase in SH fiber loading simultaneously increase water absorption properties due to hydrophilic properties of natural fiber. Plus, the composite can be improved with addition of other matrix and using GMA as a hardener instead of the main matrix.

\section{REFERENCES}

[1] Norashikin, M. Z. \& Ibrahim, M. Z. (2009). The potential of natural waste (corn husk) for production of environment friendly biodegradable film for seedling. World academy of Science, Engineering and Technology. 3: $10-26$.

[2] Kumaran, S., Sastry, C.A., \& Vikineswary, S. (1997). Laccase, cellulase and xylanase activities during growth of Pleurotus sajor-caju on sago hampas. World Journal of Microbiology and Biotechnology. 13: 43-49.

[3] Chitra, N. J. \& Vasanthakumari, R. (2012). Studies on polypropylene bio composite with corn husk waste. International Journal of Scientific \& Engineering Research. 3: 2229-5515. 
[4] Ulven, A. A. (2011). The design of biocomposite materials [PDF slides]. Retrieved from http://www.biocom.iastate.edu/workshop/2012workshop/presentations/ulven.pdf

[5] Sunarti, T.C., Dwiko, M., Derosya, V., \& Meryandini, A. (2011). Effect on microwave treatment on acid and enzymes susceptibilities of sago pith. Procedia Chemistry. 1: 1-7

[6] Lo, C. H. \& Jiang, H. (2010). Photopatterning and degradation study of dextran-glycidyl methacrylate hydrogels. Polymer Engineering and Science. 50: 232-239.

[7] Aloyarmi, T., Assaedi, H., Shaikh, F. U. A. and Low, I. M. (2014). Effect of water absorption on the mechanical properties of cotton fabric-reinforced geopolymer composites. Journal of Asian Ceramic Society. 2: 223-230.

[8] Sahari, J., Sapuan, S. M., Zainudin, E. S. \& Maleque, M. A. (2012). Effect of water absorption on mechanical properties of sugar palm fibre reinforced sugar palm starch (spf/sps) biocomposites. Journal of Biobased Materials and Bioenergy. 6: 1-5.

[9] Kiran, G. B., Suman, K. N. S., Rao, N. M., \& Rao, R. U. M. (2011). A study on the influence of hot press forming process parameters on mechanical properties of green composites using Taguchi experimental design. International Journal of Engineering, Science and Technology. 3(4): 253-263.

[10] Dhakal, H. N., Zhang Z. Y., \& Richardson M. O. W. (2006). Effect of water absorption on the mechanical properties of hemp fibre reinforced unsaturated polyester composites. Composites Science and Technology. 10.1016.

[11] Santiagoo, R., Ismail, H. \& Hussin, K. (2011). Mechanical properties, water absorption and swelling behaviour of rice husk powder filled polypropylene/ recycled acrylonitrile butadiene rubber (PP/NBRr/RHP) biocomposites using silane as coupling agent. BioResources. 6(4): 3714-3726.

[12] Crispim, E. G., Piai, J. F., Fajardo, A. R., Ramos, E. R. F., Nakamura, T. U., Nakamura, C. V., Rubira, A. F. \& Muniz, E. C. (2012). Hydrogels based on chemically modified poly(vinyl alcohol) (PVA-GMA) and PVAGMA/chondroitin sulphate: preparation and characterization. eXpress Polymer Letters. 6(5): 383-395.

[13] Pracella, M., Haque, M. M. U. \& Alvarez, V. (2010). Functionalization, compatibilization and properties of polyolefin composites with natural fibers. Polymers 2010. 2: 554-574.

[14] Han, T. L., Kumar, R. N., Rozman, H.D. \& Noor, M. A. M. (2003). GMA grafted sago starch as a reactive component in ultra violet radiation curable coatings. Carbohydrate Polymers. 54: 509-516.

[15] Razavi, N. M., Jafarzadeh, D. F., Oromiehie, A. and Langroudi, A. E. (2006). Mechanical properties and water absorption behaviour of chopped rice husk filled polypropylene composites. Iranian Polymer Journal. 15: $757-766$.

[16] Taib, R. M., Ramarad, S., Ishak, Z. A. M., Todo, M. (2008). Water absorption and tensile properties of kenaf bast fiber-plasticized poly(lactic acid) biocomposites. Proceeding of the Polymer Proceeding Society $24^{\text {th }}$ Annual Meeting. Solerno, Italy. June 15-19 $9^{\text {th }}, 2008$.

[17] Gutierrez, T. J., Perez, E., Guzman, R., Tapia, M. S., Fama, L (2014). Physicochemical and functional properties of native and modified by crosslinking, dark-cush-cush yam (dioscorea trifida) and cassava (manihot esculenta) starch. Journal of polymer and Biopolymer Physics Chemistry. 2(1): 1-5.

[18] Janggu, U. and Bujang, K.B. (2008). Development of Cellulose Treatments Procedures for Production of Fermentable Sugars from Sago Hampas for Ethanol Fermentation. 10th Symposium of the Malaysian Society of Applied Biology. 6-8 ${ }^{\text {th }}$ November 2008. Kuching, Sarawak, Malaysia.

[19] Mandal, A., Pan, S., Mukherjee, S., Saha, A. K., Thomas, S. \& Sengupta, A. (2014). Variations in specific heat and microstructure in natural rubber filled with different fillers as studied by differential scanning calorimetry. Journal of Polymer and Biopolymer Physics Chemistry. 2(1): 25-28.

[20] Nigam, P.S., \& Pandey, A. (2009). Utilization of agro-residues. Biotechnology for Agro-Industrial Residues. 10: 978-1007.

[21] Roeder, R. K., Converse, G. L., Kane, R. J. \& Yue, W. (2006). Hydroxyapatite-reinforced polymer biocomposites for synthetic bone substitutes. Biological Material Science. 1: 38-45. 